\title{
IGRA based diagnosis of infection and prediction of disease
}

\author{
Peter Andersen 1,2 \\ From Immunodiagnosis of Tuberculosis: New Questions, New Tools \\ Virginia, VA, USA. 21-23 September 2008
}

Can IGRA assays, used in the highly specific and sensitive quantiFERON and T-spot tests, predict the development of disease in individuals who are infected but currently display no symptoms? High ESAT-6 reactivity may predict disease because ESAT- 6 is a marker for bacterial burden. We found that vaccinated cattle for which the vaccine did not offer protection displayed high reactivity to ESAT- 6 early in infection; cattle that controlled the infection displayed low ESAT-6 reactivity. By evaluating the response in guinea pigs both vaccinated and not vaccinated with BCG, we found that the animals with a large skin test result (high reactivity) after infection with Mycobacterium tuberculosis did not have a long survival time. In mouse vaccination studies ESAT-6 reactivity dropped as the vaccine controlled bacterial activation, which indicates that ESAT- 6 reactivity correlates with the dynamics of infection.

For humans, we developed a template to use as a cutoff or conversion model for predicting three possible scenarios for individuals post-exposure. The model, based on IFN- $\gamma$ levels in response to ESAT-6, delineates three possible reactions: people who control initial bacterial replication and remain ESAT-6 negative; people who fail to control initial replication, but eventually control the infection, becoming ESAT-6 positive and latently infected; people who fail to control replication, become ESAT-6 positive and later develop clinical TB. A large study with serial quantitative IGRA testing is necessary to be able to make a statistically robust ROC curve.

ESAT-6/CFP10 has great value as a predictor of TB disease. In low/meso-endemic regions, ESAT-6/CFP10 predicts progression to disease with higher accuracy

\footnotetext{
Correspondence: PA@ssi.dk

${ }^{1}$ Infectious Disease Immunology, Statens Serum Institute, Copenhagen, Denmark

Full list of author information is available at the end of the article
}

than PPD, resulting in more precise targeting, preventive therapy and less treatment. In high endemic regions, the potential for TB prediction may depend on the establishment of a cut-off or QFT conversion that would allow the identification of QFT positive individuals at the highest risk of progression. If longitudinal monitoring of ESAT- 6 reactivity levels is used as a biomarker of bacterial replication, it can also be useful as a clinical endpoint, allowing for much shorter clinical trials of both vaccines and novel drugs.

\section{Author details}

'Infectious Disease Immunology, Statens Serum Institute, Copenhagen, Denmark. ${ }^{2}$ Vaccine R\&D, Statens Serum Institute, Copenhagen, Denmark.

Published: 17 December 2010

doi:10.1186/1753-6561-4-S3-015

Cite this article as: Andersen: IGRA based diagnosis of infection and prediction of disease. BMC Proceedings 2010 4(Suppl 3):O15.

Submit your next manuscript to BioMed Central and take full advantage of:

- Convenient online submission

- Thorough peer review

- No space constraints or color figure charges

- Immediate publication on acceptance

- Inclusion in PubMed, CAS, Scopus and Google Scholar

- Research which is freely available for redistribution

Submit your manuscript at www.biomedcentral.com/submit
Biomed Central 